\title{
Probable Carboxypeptidase X1
}

National Cancer Institute

\section{Source}

National Cancer Institute. Probable Carboxypeptidase X1. NCI Thesaurus. Code C131754.

Probable carboxypeptidase X1 (734 aa, $\sim 82 \mathrm{kDa}$ ) is encoded by the human CPXM1 gene.

This protein may be involved in the interactions between cells. 